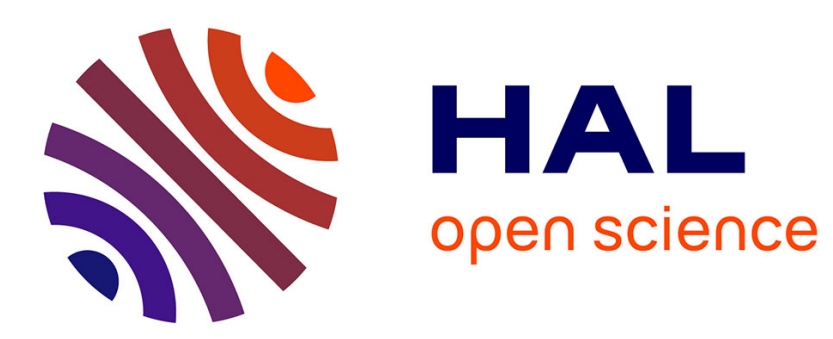

\title{
Which Model of Technology Transfer for Nanotechnology? A Comparison with Biotech and Microelectronics
}

Corine Genet, Khalid Errabi, Caroline Gauthier

\section{- To cite this version:}

Corine Genet, Khalid Errabi, Caroline Gauthier. Which Model of Technology Transfer for Nanotechnology? A Comparison with Biotech and Microelectronics. Technovation, 2012, 32 (3-4), p. 205-215. 10.1016/j.technovation.2011.10.007 . hal-00749152

\section{HAL Id: hal-00749152 \\ http://hal.grenoble-em.com/hal-00749152}

Submitted on 6 Dec 2012

HAL is a multi-disciplinary open access archive for the deposit and dissemination of scientific research documents, whether they are published or not. The documents may come from teaching and research institutions in France or abroad, or from public or private research centers.
L'archive ouverte pluridisciplinaire HAL, est destinée au dépôt et à la diffusion de documents scientifiques de niveau recherche, publiés ou non, émanant des établissements d'enseignement et de recherche français ou étrangers, des laboratoires publics ou privés. 


\title{
WHICH MODEL OF TECHNOLOGY TRANSFER FOR NANOTECHNOLOGY?
}

\section{A Comparison with Biotech and Microelectronics}

\author{
Corine Genet, Khalid Errabi, Caroline Gauthier \\ Grenoble Ecole de Management (GEM) \\ 12 rue Pierre Sémard, 38000 Grenoble, France \\ Phone: + 33476706297 \\ Contact e-mail: corine.genet@grenoble-em.com \\ Website: www.nanoeconomics.eu
}

\begin{abstract}
.
Nanotechnologies are often presented as breakthrough innovations, where technology transfer and knowledge-bridging will play a pivotal role in the industrial dynamics. This article investigates the model of knowledge transfer in the nanotechnologies in depth, by comparing it with the models of two recently emerged technologies: biotech and microelectronics. Our results show that the nanotechnology transfer model is very different from that involved in biotechnology evolution: while small-medium firms play a valuable technology-bringing role, the central function of "translating" new knowledge between public research and industry in carried by the larger firms, just as it was in the early stages of the microelectronics sector.
\end{abstract}

\section{Keywords.}

Nanotechnology - biotechnology - microelectronics - technology transfer

Acknowledgements: we acknowledge the financial support of ANR (ANR-07-NANO-02601). The authors would like to thank the participants of COMS2010 Alburquerque, USA and the participants of the MCOI seminar (www.grenoble-innovation.eu) at Grenoble Ecole de Management. We are grateful to Jon Morgan for his paper editing. Usual caveats apply. 


\title{
WHICH MODEL OF TECHNOLOGY TRANSFER FOR NANOTECHNOLOGY?
}

\section{A Comparison with Biotech and Microelectronics}

\begin{abstract}
.
Nanotechnologies are often presented as breakthrough innovations, where technology transfer and knowledge-bridging will play a pivotal role in the industrial dynamics. This article investigates the model of knowledge transfer in the nanotechnologies in depth, by comparing it with the models of two recently emerged technologies: biotech and microelectronics. Our results show that the nanotechnology transfer model is very different from that involved in biotechnology evolution: while small-medium firms play a valuable technology-bringing role, the central function of "translating" new knowledge between public research and industry in carried by the larger firms, just as it was in the early stages of the microelectronics sector.
\end{abstract}

\section{Keywords.}

Nanotechnology - biotechnology - microelectronics - technology transfer

\section{Introduction}

It seems likely that the nanotechnology will be a significant factor in the $21^{\text {st }}$ century. The U.S. National Nanotechnology Initiative (NNI) has defined nanotechnology as "encompassing the science, engineering, and technology related to the understanding and control of matter at the length scale of approximately one to 100 nanometers". Nanotechnologies include the research and development of materials, devices, and systems that have novel properties and functions due to their nanoscale structures or components (Chen and Roco 2009).They offer the potential for ground-breaking scientific research, and hold out the promise both of increasing efficiency in traditional industries, and of fostering radically new applications in emerging technologies. Nanotechnologies are expected to have a huge positive impact on economic growth and to create new markets, which is why most industrialized countries and 
companies have invested billions of dollars in nanotech developments, and are expecting great returns.

Nanotechnologies are technologically multidisciplinary as well as have cross-industrial utility (Linton and Walsh 2004): product and process applications have been and are being developed in areas ranging from medicine, electronics, optics, telecommunications, aerospace to energy (Niosi 2007). Nanotechnology is seen as a breakthrough innovation, with technology transfer and knowledge-bridging playing a pivotal role in its birth and growth (Rothaermel and Thursby 2007). This article investigates the model of technology transfer in the nanotech sector in depth in order to guide decision-makers in making the right choices for its further developments. To do so, we compare the case of the evolution of nanotech with those of two other recently emerged technologies - biotechnology and microelectronics: each of which has held out the innovative prospect of producing existing products using a completely different set of technical competencies (Walsh and Kirchhoff 2002). Linton and Walsh (2004) describe them as 'materials based technologies with concurrent product and process innovation curves and regard them as the likely engines of future economic growth'.

Nanotechnologies are often compared to biotechnologies, due to the breakthroughs the latter have generated in the pharmaceutical industry (Zucker et al., 2007). The integration of nanotechnologies could threaten the leadership of established firms in the same way, rendering their accumulated expertise redundant (Hill et al., 2003), and creating emerging opportunities for new firms (Shea, 2005). Such new entrants are better placed to take advantage of disruptive technologies than are incumbents, who may suffer from organizational inertia and short-term incentives, and face the prospect of having to cannibalize their own markets. If the comparison (with biotechnologies) holds, small-medium firms (SMEs) are likely to play a key role in the industrial dynamics of nanotechnologies, leading to industrial architectures mainly composed of dedicated spin-offs focused on bringing nanotechnology processes, tools and first generation materials, devices and systems to market (Chachamidou and al. 2008).

But nanotechnologies can also be compared to microelectronics, although here the comparison seems to point to a different industrial landscape. As Abernathy and Utterback (1978) have highlighted, large firms such as Fairchild Semiconductors, IBM and Texas Instruments played the fundamental roles in this field's first development phases in the 60s and 70s. The development of nanotechnologies requires the same kind of large knowledge 
base that incumbent firms possess, implying that large firms will predominate in both the exploration and commercialization of nanotechnology potentials, and that small-medium firms will play lesser roles.

This paper focuses on the place of small-medium firms in the knowledge transfer model of this new technology, addressing the questions of: What role do SMEs play in the coproduction and translation of knowledge? Is it central, as it is in the biotech sector? Are they one of several avenues via which knowledge and technology is transferred from academe to industry? Or do they play a role similar to how SMEs operate in the microelectronic sector, as suppliers of specific equipment to large companies? To explore the model of technology transfer in nanotechnology, we have built a database of the (approx) 10,000 firms that patented in nanotechnologies between 1990 and 2008, using a validated search strategy based on keywords (Mogoutov et al., 2007) to extract patents from PatStat. The database was crossreferenced against ORBIS to retrieve firms' financial data, as well as to identify and then extract small-medium firms

The paper is structured as follows. Firstly, we question the model of knowledge transfer in nanotechnology by considering the technological evolutionary patterns of the biotechnology and microelectronics industries. We then describe our empirical data and methods of analysis, and lastly present and discuss our results.

\section{Are the knowledge transfer models of nanotechnology, biotechnology and microelectronics similar?}

\section{Comparing nanotechnology with biotechnology}

Many scholars (Rothaermel and Thursby 2007; Zucker and Darby 2007; Niosi 2007; Youties et al. 2008) have found that nanotechnology and biotechnology have exhibited similar technological evolutionary patterns. The pattern of biotechnology development has largely been based on the creation of research-intensive SMEs (Orsenigo, 1989, 2001; Gambardella, 1995; Sharp 1985, Kenney, 1986), usually university spin-offs formed through the collaboration of a scientist and a professional manager, backed by venture capital, with the aim of applying new scientific discoveries to commercial product development (Mangematin et al. 2003). In many cases these spin-offs benefited from access to top world experts (usually university scientists) on specific topics, and the firms' expertise has essentially been in 
research areas directly related to the scientific field of their expert's original laboratory. The product of such firms has exclusively almost been research within a relatively narrow range, and - in terms of their ability to translate their research into innovations - these small-medium firms have typically lacked critical assets in manufacturing, testing and marketing areas, access to regulatory agencies and to distribution channels in the pharmaceutical and food industries. In order to integrate such biotechnology innovation capabilities, SMEs have had to develop different forms of collaboration with established firms. It has been argued that since large pharmaceutical companies were committed to the old organic chemistry paradigm, where all their competences were concentrated, they could not easily internalize the new biotechnological knowledge; and that few of them had the absorptive capacity required to internalize the new paradigm or could construct such a capacity rapidly (Pyka and Saviotti, 2005). So these collaborative arrangements between small and large firms provided both partners with access to the competences and assets they lacked: large companies to the SMEs' scientific discoveries - and the potential of receiving royalties if they had commercial potential - and SMEs to commercial markets. Consequently, the biotechnology industry is characterized by a network structure of inter-organizational alliances among the different actors involved: research institutions and large and small-medium firms, in which the latter are seen as a nexus, mediating between the scientists and the large established commercial players (Mangematin et al. 2003).

In such frameworks, the SMEs play a key role in the process of co-producing and translating knowledge, acting essentially as intermediaries bridging the gap between public research institutions and large chemical and pharmaceutical companies, buying research outputs from their discoverers, developing or refining them towards specific objectives, and then selling this knowledge on to larger partners for downstream commercialization (Greis et al., 1995; Zucker and Darby, 1997). Orsenigo (1989) argues that this specialization of biotech start-ups “... provided an institutional solution to the transfer problem" and Orsenigo et al. (2001) refer to these new organizations as "specialized technology originators", while Pyka and Saviotti (2005) refer to their role as "translators". The biotech technology transfer model thus has SMEs as central economic actors.

Zucker and Darby (2007) show that the evolution of nanotechnology is following the same pattern: firms are entering where and when academics scientists publish breakthrough articles. They suggest that the production of nanotechnological knowledge is embedded in the wider social context of cross-institutional collaboration, and expect development patterns to be 
based on strong ties between academe and industry leading to the creation of spin-offs. In their framework, the process of knowledge transfer from science and engineering to industrial application involves academic (Zucker and Darby 2007). Top scientists' involvement contributed importantly to the appropriability of biotechnology inventions, and a similar process appears to have started in nanotechnology (Zucker and Darby 2007). In such hightechnology sectors as biotechnology or nanotechnology, newly founded firms have been perceived as the main drivers of technological change, and we could this argue that this type of actor is likely to be in a better position than larger firms to exploit the new opportunities created by the emergence of nanotechnologies. To examine whether the technological transfer model of nanotechnology mirrors that of the biotechnology industry in terms of the role of SMEs, we test:

Proposition \# 1: Do SMEs play a key role in co-producing and transferring knowledge in nanotechnology by acting as a node of high centrality between public research and large firms in nanotech co-patenting networks.

\section{Comparing nanotechnology with microelectronics}

Abernathy and Utterback (1978), Peck (1986) and Braun and MacDonald (1978) have stressed the fundamental role that large firms played in the early stages of the microelectronics industry. Peck (1986) and Levin (1982) point out that there was no profound interaction between scientific theory and technological practice during the first years of the development of the transistor: the integrated circuit concept did not rest on any novel application of scientific theory: rather it was an engineering achievement. In the same vein, Mowery (1983) argues that the evolution of the industry structure is best explained by reference to the central role of manufacturing processes: "the pure science input into semiconductor innovation currently is rather modest; it is production engineering that is critical." Arcangeli et al. (1991) highlighted that the accumulation of knowledge in the early stage of microelectronics industry was mainly based on the history, technical knowledge and forms of corporate organization inherited from electromechanical technologies. Braun and MacDonald (1978) explained that, in the first two decades of the computer and semiconductor industries, large integrated producers (such as AT\&T and IBM) designed their own solid-state components, manufactured the majority of the capital equipment used in their production process and utilized internally produced components in the manufacture of electronic computers and computer software that was leased or sold to their customers. 
However Levin (1982) points out that, by the late 1970s, technical progress increasingly required more research than had characterized industry's early stage, while Peck (1986) notes that three entities were already positioned with large programs to carry out such research: IBM, AT\&T and the large Japanese computer and semiconductor firms, and that large-scale R\&D projects carried out jointly by profit-making corporations became increasingly important in the computer and semiconductor industries. These efforts - largely organized and funded by governments - generally focused on longer term generic research, leaving product and process development to smaller individual companies, thus making up for the small scale their research capabilities. In that framework, a few large firms played the fundamental roles in the process of knowledge co-production, based on partnerships created in the early stage of the microelectronics industry. Thus internal $R \& D$ and large-scale research projects which involved both large companies and public research seems to have been the principal vector of the co-production and transfer of knowledge, positioning the large firms as the central economic actors. A recent paper by Mangematin et al. (2010) argues that, in nanotechnology development, large firms hybridize their existing knowledge base with these newly emerging technologies, and shows how they are investing in pre-adaptation so as to speed up the development of new technologies and to be ready as markets emerge. This pattern suggests that the nanotech technology transfer model is closer to that of microelectronics, with large firms having the fundamental role, and contention which we examine in this paper by testing a second proposition:

Proposition \# 2: Do large firms play a fundamental role in co-producing and transferring knowledge in nanotechnology by acting as a node of high centrality directly linking the industry's co-patenting network with public research in nanotechnology.

\section{Data and Methodology}

\section{Data acquisition}

To explore these two propositions, we built a database of firms involved in nanotechnologies, to develop a data set of nanotechnology-related patents from 1998-2006, which were collected from the PATSTAT EPO database (which collects data coming from 73 offices worldwide). We identified 617,000 nanotechnology applications from the more than 65,000,000 patents listed PATSTAT in our focal period, and used a keyword-based approach to select a subset of 
the patents related to nanotechnologies (Mogoutov et al. 2007). We ended up with 9,447 companies that had patented in nanotechnologies.

We matched this database with ORBIS to discover economic and financial information about our data set firms. ORBIS is a comprehensive world-wide database of information on 60 million companies, combining information from nearly 100 sources filtered into various standard report formats. This search found 3,719 firms involved in nanotechnology (which we label "nanotech firms"). ORBIS define four categories of firms: (VL) Very Large companies (operating revenue of at least US\$40m or over 1000 employees), (L) Large companies (operating revenue at least US\$14m or over 150 employees), (M) Medium sized companies (operating revenue at least US\$ 1.4 million or over 15 employees and (S) Small companies (those not included in another category). Using this classification, we identified 2,140 (58\%) of our nanotech firms as being large or very large firms, and 1,579 (42\%) as being small or medium firms (SMEs).

Tables 1, 2, 3 and 4 describe the main characteristics of our population of 3,719 nanotech firms. ${ }^{1}$ We observe that $71 \%$ of nanotech SMEs were created after 1990. Since the potential of understanding the nanoscale properties of matter and the formulation of key research opportunities were becoming clearer by 2000 (Roco, Williams and Alivisatos, 2000) - we can suppose that these firms were created to apply these new scientific discoveries to commercial product development. In contrast, $70 \%$ of large-very nanotech large firms were created before 1990: we can characterize these firms as investing in nanotechnology, but being not dedicated nanotech companies.

\footnotetext{
${ }^{1}$ The data preparation and the statistical analysis for this paper were generated using SAS software. Copyright, SAS Institute Inc.
} 
Table 1 Firm's Size by Year of Incorporation

\begin{tabular}{|c|c|c|c|c|c|}
\hline \multicolumn{6}{|l|}{$\begin{array}{l}\text { Frequency } \\
\text { Percent } \\
\text { Row Pct } \\
\text { Col Pct }\end{array}$} \\
\hline \multirow{2}{*}{$\begin{array}{l}\text { Firm's Size -2 Levels- } \\
\text { (ORBIS) }\end{array}$} & \multicolumn{5}{|c|}{ Year of Incorporation } \\
\hline & pre-1950 & 1951-1980 & 1981-1990 & post 1990 & Total \\
\hline \multirow[t]{4}{*}{ SM Firms } & 43 & 147 & 265 & 1,124 & 1,579 \\
\hline & 1.16 & 3.95 & 7.13 & 30.22 & 42.46 \\
\hline & 2.72 & 9.31 & 16.78 & 71.18 & \\
\hline & 6.23 & 23.11 & 42.47 & 63.54 & \\
\hline \multirow[t]{4}{*}{ LVL Firms } & 647 & 489 & 359 & 645 & 2,140 \\
\hline & 17.40 & 13.15 & 9.65 & 17.34 & 57.54 \\
\hline & 30.23 & 22.85 & 16.78 & 30.14 & \\
\hline & 93.77 & 76.89 & 57.53 & 36.46 & \\
\hline Total & 690 & 636 & 624 & 1,769 & 3,719 \\
\hline \%age & 18.55 & 17.10 & 16.78 & 47.57 & 100.00 \\
\hline
\end{tabular}

Table 2 shows that about $90 \%$ of nanotech SMEs are located in Europe and US/Canada (while large-very large nanotech firms are mostly located in Europe (48\%) and US Canada (24\%) but also in Asia (21\%). Mangematin et al. (2010) have shown that the investment of Asian firms in nanotechnology is mainly centered on nanoelectronics, a sector that remains dominated by large companies.

Table 2 Firm Size by Geographical Area

\begin{tabular}{|c|c|c|c|c|c|}
\hline $\begin{array}{l}\text { Frequency } \\
\text { Percent } \\
\text { Row Pct } \\
\text { Col Pct }\end{array}$ & & & & & \\
\hline \multirow{2}{*}{$\begin{array}{l}\text { Firm's Size -2 Levels- } \\
\text { (ORBIS) }\end{array}$} & \multicolumn{5}{|c|}{ Geographical Area } \\
\hline & ASIA & EU27 & OTHERS & US/Canada & Total \\
\hline \multirow[t]{4}{*}{ SM Firms } & 60 & 669 & 101 & 749 & 1,579 \\
\hline & 1.61 & 17.99 & 2.72 & 20.14 & 42.46 \\
\hline & 3.80 & 42.37 & 6.40 & 47.44 & \\
\hline & 11.95 & 39.35 & 39.92 & 59.26 & \\
\hline \multirow[t]{4}{*}{ LVL Firms } & 442 & 1031 & 152 & 515 & 2,140 \\
\hline & 11.88 & 27.72 & 4.09 & 13.85 & 57.54 \\
\hline & 20.65 & 48.18 & 7.10 & 24.07 & \\
\hline & 88.05 & 60.65 & 60.08 & 40.74 & \\
\hline Total & 502 & 1,700 & 253 & 1,264 & 3719 \\
\hline \%age & 13.50 & 45.71 & 6.80 & 33.99 & 100.00 \\
\hline
\end{tabular}

Table 3 shows that $42 \%$ of nanotech SMEs have high nano patenting intensity (more than $50 \%$ ), but $60 \%$ of the large nanotech firms have nano patenting intensities of less than $10 \%$. 
Table 3 Firm's Size by Nano Patenting Intensity

\begin{tabular}{|c|c|c|c|c|c|}
\hline \multicolumn{6}{|l|}{$\begin{array}{l}\text { Frequency } \\
\text { Percent } \\
\text { Row Pct } \\
\text { Col Pct }\end{array}$} \\
\hline \multirow{2}{*}{$\begin{array}{l}\text { Firm's Size -2 Levels- } \\
\text { (ORBIS) }\end{array}$} & \multicolumn{5}{|c|}{ Company's Nano Patenting Intensity } \\
\hline & $\begin{array}{c}\text { LOW } \\
(<10 \%)\end{array}$ & $\begin{array}{l}\text { MEDIUM } \\
(\mathbf{1 0}-<\mathbf{5 0 \%})\end{array}$ & $\begin{array}{c}\text { HIGH } \\
(50-<100 \%)\end{array}$ & $\begin{array}{c}\text { ULTIMATE } \\
(100 \%)\end{array}$ & Total \\
\hline \multirow[t]{4}{*}{ SM Firms } & 293 & 621 & 368 & 297 & 1,579 \\
\hline & 7.88 & 16.70 & 9.90 & 7.99 & 42.46 \\
\hline & 18.56 & 39.33 & 23.31 & 18.81 & \\
\hline & 18.58 & 51.45 & 70.23 & 72.26 & \\
\hline \multirow[t]{4}{*}{ LVL Firms } & 1,284 & 586 & 156 & 114 & 2,140 \\
\hline & 34.53 & 15.76 & 4.19 & 3.07 & 57.54 \\
\hline & 60.00 & 27.38 & 7.29 & 5.33 & \\
\hline & 81.42 & 48.55 & 29.77 & 27.74 & \\
\hline Total & 1,577 & 1,207 & 524 & 411 & 3,719 \\
\hline \%age & 42.40 & 32.45 & 14.09 & 11.05 & 100.00 \\
\hline
\end{tabular}

Table 4 lists the main industrial sectors where our 3,719 nanotech firms operate, based on the North American Industry Classification System (NAICS), and shows that nanotech SMEs are mainly involved in the Professional, Scientific and Technical Services sector (20\%), while large-very large nanotech firms are mainly found in the Pharmaceutical and Medicine Manufacturing, the Control Instrument and the Semiconductor and Other Electronic Component Manufacturing sectors.

Table 4 Firm's Size by industry

\begin{tabular}{|c|c|c|c|}
\hline $\begin{array}{l}\text { Frequency } \\
\text { Percent } \\
\text { Row Pct } \\
\text { Col Pet }\end{array}$ & & & \\
\hline & Firm's Size - & Levels-(OR & IS) \\
\hline NAICS 2007 & LVL Firms & SM Firms & Total \\
\hline Scientific Research and Development Services & 93 & 312 & \\
\hline & 2.50 & 8.39 & 405 \\
\hline & 22.96 & 77.04 & 10.89 \\
\hline & 4.35 & 19.76 & \\
\hline Pharmaceutical and Medicine Manufacturing & 203 & 46 & \\
\hline & 5.46 & 1.24 & 249 \\
\hline & 81.53 & 18.47 & 6.70 \\
\hline & 9.49 & 2.91 & \\
\hline Navigational, Measuring, Electromedical and Control & 129 & 89 & \\
\hline Instruments Manufacturing & 3.47 & 2.39 & 218 \\
\hline & 59.17 & 40.83 & 5.86 \\
\hline & 6.03 & 5.64 & \\
\hline Semiconductor and Other Electronic Component & 134 & 68 & 202 \\
\hline
\end{tabular}




\begin{tabular}{|lrrr|}
\hline Manufacturing & 3.60 & 1.83 & 5.43 \\
& 66.34 & 33.66 & \\
\hline Total & $\mathbf{6 . 2 6}$ & 4.31 & \\
\hline \%age & 2,140 & 1,579 & 3719 \\
\hline
\end{tabular}

According to the NAICS, the Professional, Scientific and Technical Services sector is specialized, and provides services to clients in a variety of industries and (in some cases) to households. Activities performed include (and involve expertise in): legal advice and representation; accounting, bookkeeping and payroll services; architectural, engineering and specialized design services; computer services; consulting services; research services; advertising services; photographic services; translation and interpretation services; veterinary services etc.. It can be argued that these activities represent valuable ways in which nano technologies can be exploited in client companies' innovation processes and, therefore, it is reasonable to expect that nanotech SMEs play a critical knowledge-bridging role in such situations.

\section{Network construction}

The network concept is a relatively new methodology that is used in many disciplines including economics, sociology and organizational theory - to analyze different interaction structures among actors. Developed within the framework of graph theory, it is increasingly used to study industry networks composed of different but interrelated groups of actors (e.g., firms, suppliers, customers, universities, and other institutions). To capture the role of SMEs in the process of nanotech knowledge co-production, we introduce network concepts and measures to represent the relations between such different actors as universities, nonprofit institutions, governmental institutions, hospitals and companies, focusing on technological collaboration expressed through co-patenting. Niosi (2007) reminds us that patents are key to protecting intellectual propriety in both the biotechnology and nanotechnology arenas and, despite the objection that patents are by definition static and may thus represent incomplete criteria with which to measure knowledge flows, we argue that co-patent networks offer a valuable way of examining $R \& D$ collaboration structures (Goetze C., 2010) because they mirror the results of collaborations between actors.

We use two different analytical units in this research. We first analyze institutions' copatenting networks in a way that represents each category of actor involved: universities, 
nonprofit institutions, governmental institutions, hospitals and firms, which are represented according to size (small-medium or large-very large). Second, we analyze co-patenting networks at the firm level. In both network models, nodes represent the analytical units categories of institution (universities, nonprofit institutions, governmental institutions, hospitals and firms) in the first network and firms in the second - and links represent the copatent relations between different actors. Visualizing core networks allows us to identify the salient collaborations between actors and thus infer the role of firms in the nanotechnology knowledge transfer model. We adopted Cytoscape Collaboration's open-source network visualization and analysis software in developing our framework. ${ }^{2}$

\section{Network analysis}

First, we undertook a topological analysis of the two types of co-patenting networks, a technique that characterizes them via various statistical measures (Albert and Barabasi, 2002):

- Network size: shows the coverage of the field and reports the number of nodes and number of links;

- Component size: A component is an isolated sub-network in a disconnected network, and thus represents a independent group in the field;

- Density: is understood as the number of all realized links divided by the number of all possible ones (Wasserman and Faust, 1994);

- Network diameter: indicates the distance between the two most distant nodes (i.e. the longest 'shortest path' between any node couple on the graph);

- Average path length (or Average Distance) is the average length of the shortest nodecouple paths (calculated by summing all the shortest paths and then dividing by the total number of node couples);

- Degree: is the simplest topological index, corresponding to the number of nodes adjacent (i.e., directly connected) to a given node (also called its "first neighbors") ;

- Average degree: is the average number of links a node has with other nodes;

- Average Clustering coefficient: is the average of all the nodes' clustering coefficients. A single node's clustering coefficient is the ratio of the number of links between the node's neighbors (the nodes directly connected to it) to the number of possible links between them. The co-patent network's average coefficient thus indicates the tendency

\footnotetext{
${ }^{2}$ Cytoscape is a collaborative project between the Institute for Systems Biology (Leroy Hood lab), the University of California San Diego (Trey Ideker lab), Memorial Sloan-Kettering Cancer Center (Chris Sander lab), the Institut Pasteur (Benno Schwikowski lab), Agilent Technologies (Annette Adler lab) and the University of California, San Francisco (Bruce Conklin lab). (http://www.cytoscape.org).
} 
for analytical units to form 'local' clusters, with denser local clusters indicating nodes that are more likely to be influenced by their neighbors.

Secondly, since we are focusing on centrality, which concerns the roles of individuals (in our case, firms) in a network, we measure several related factors (such as degree, closeness, betweenness and eccentricity).

- Degree: is the number of direct links a particular node has;

- Eccentricity: of a node is calculated by computing the shortest path between it and all other nodes on the graph;

- Closeness: The closeness of a node is calculated by computing the shortest paths between it all the other nodes in the graph and summing these values. Closeness should be always compared to eccentricity: a node with high eccentricity + high closeness is very likely to be central on the graph (and thus to the network);

- Betweenness: provides an elaborated and informative centrality index, and counts the number of shortest paths linking a node couple (v1, v2) and passing through another node $n$.

From these topological measures and centrality parameters, we can identify the co-patent network's global structure and infer the role of firms in the nanotechnology knowledge transfer model.

\section{Findings and discussion}

\section{Small-medium firms do not operate as intermediaries between science and industry in nanotechnologies}

The nanotechnology co-patent institution network is shown in Figure 1 and the main topological parameters in Table 1. Nodes represent categories of institution: universities, nonprofit institutions, governmental institutions, hospitals and firms. Links represent the copatent relations between different actors (analytical units), with line widths reflecting the strength of the links between two nodes. 


\section{Large firms are central in the nanotechnology firm co-patenting network}

Figure 2 visualizes the co-patenting network activity among our 3,719 firms. The network density is very low and there are 2,865 isolated nodes and, in activity terms, only 854 firms (23\%) co-patent with other firms. The network's topological measures (Table 2) show that the network contains 3,001 connected components, and the average number of neighbors is less than 1.

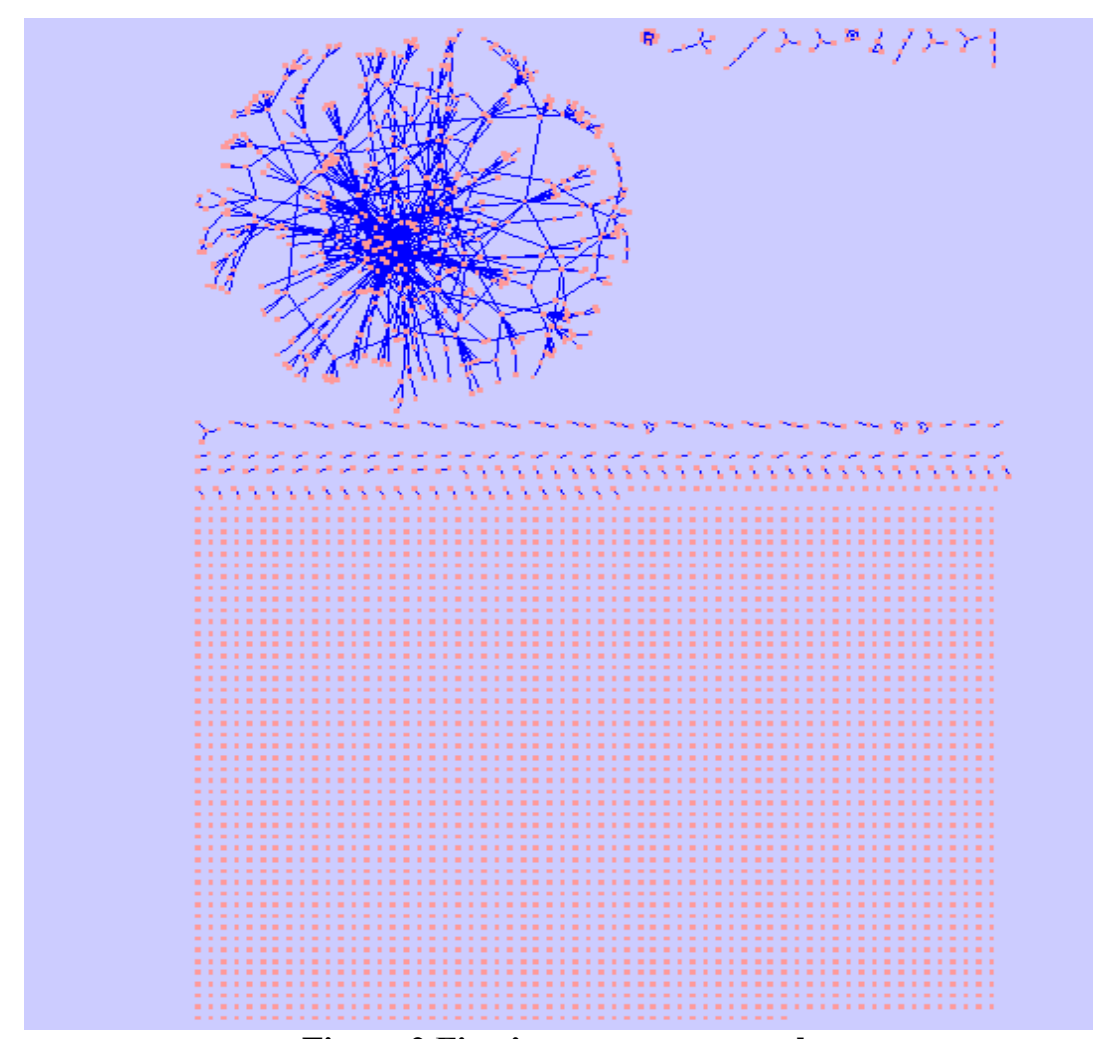

Figure 2 Firm's co-patent network

$\begin{array}{rr}\text { Clustering coefficient : } \mathbf{0 . 0 1 9} & \text { Number of nodes : } \mathbf{3 7 1 9} \\ \text { Connected components : } \mathbf{3 0 0 1} & \text { Number of edges : } \mathbf{4 7 1 5} \\ \text { Network diameter : } \mathbf{1 5} & \text { Network density : } \mathbf{0 . 0 0 0} \\ \text { Network radius : } \mathbf{1} & \text { Network heterogeneity : } \mathbf{3 . 5 3 8} \\ \text { Network centralization : } \mathbf{0 . 0 1 1} & \text { Isolated nodes : } \mathbf{2 8 6 5} \\ \text { Shortest paths : } \mathbf{2 8 4 0 9 6 ( 2 \% )} & \text { Number of self-loops : } \mathbf{3 7 1 9} \\ \text { Characteristic path length : } \mathbf{5 . 4 5 0} & \text { Multi-edge node pairs : } \mathbf{0} \\ \text { Avg. number of neighbors : } \mathbf{0 . 5 3 6} & \text { Analysis time (sec) : } \mathbf{0 . 7 1 8}\end{array}$

Table 2 Topological measures of the firm's co-patenting network

To gain finer-grained information, we focused our analysis on the core of the network (Figure 3), which yielded a testbed of 533 firms, 1,315 co-patent relations, and 533 self-patent relations. The topological measures of the main firm co-patenting network (Table 3) shows that at least one path exists between every pair of nodes - in other word every firm in this core area of the network directly or indirectly affects another through co-patenting in nanotechnology R\&D. 


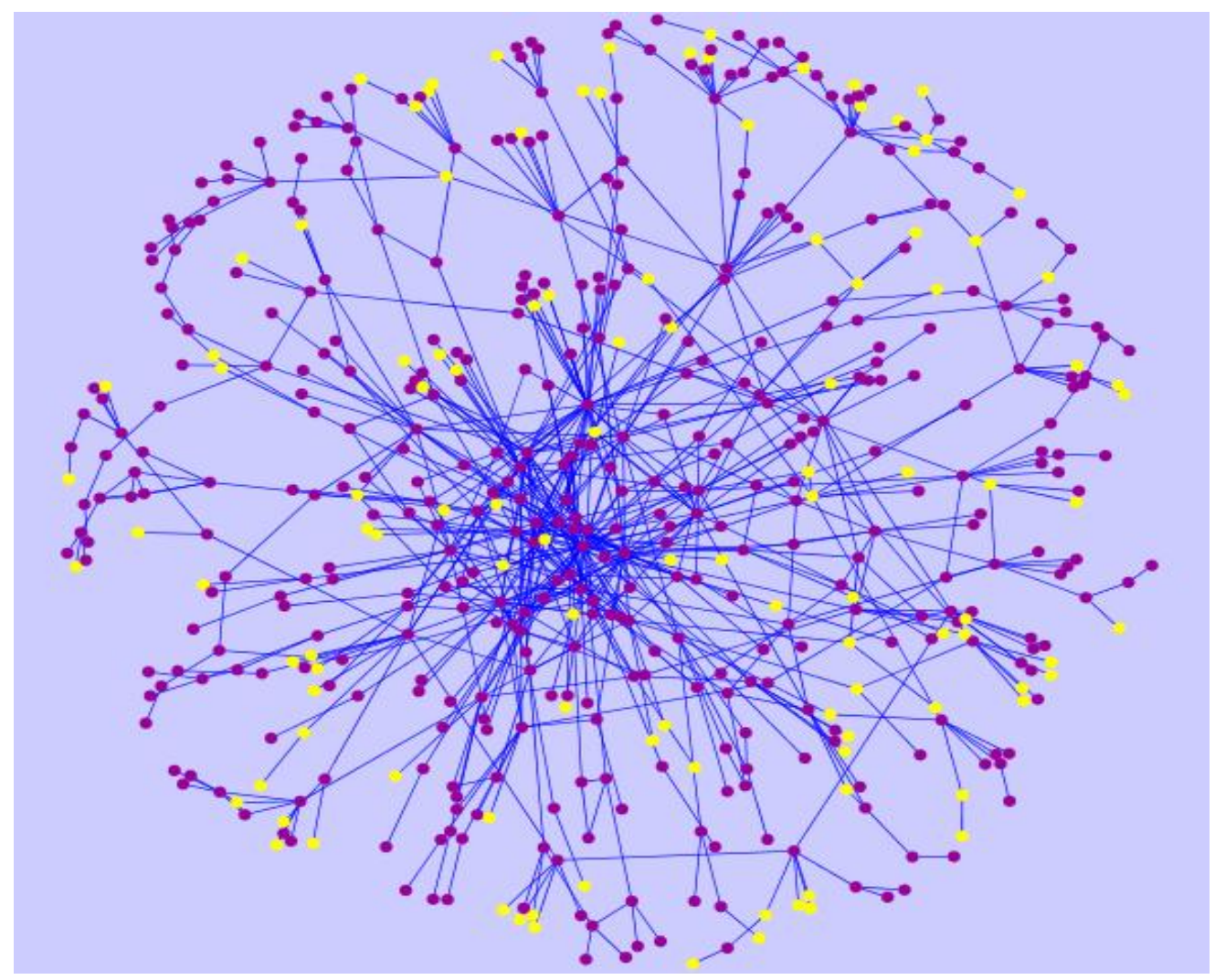

SMEs

LVL Firms

Figure 3 Main firm's co-patenting network colored by firm's size

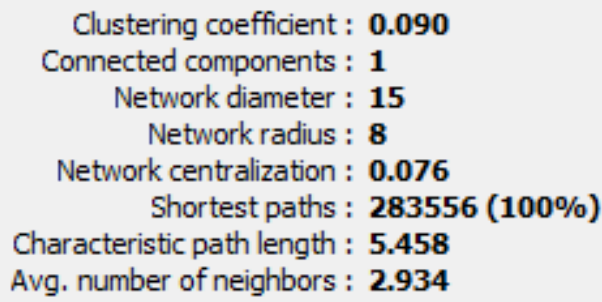

Clustering coefficient : $\mathbf{0 . 0 9 0}$

Connected components : $\mathbf{1}$

Network diameter : 15

Network radius : $\mathbf{8}$

Network centralization : $\mathbf{0 . 0 7 6}$

Shortest paths : $283556(\mathbf{1 0 0} \%)$

Characteristic path length : $\mathbf{5 . 4 5 8}$

Avg. number of neighbors : 2.934

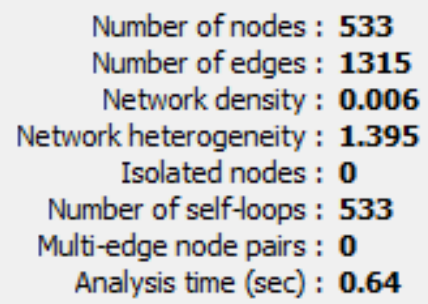

Number of nodes : $\mathbf{5 3 3}$

Number of edges : $\mathbf{1 3 1 5}$

Network density : $\mathbf{0 . 0 0 6}$

Network heterogeneity : $\mathbf{1 . 3 9 5}$ Isolated nodes : 0

Number of self-loops : $\mathbf{5 3 3}$

Multi-edge node pairs : $\mathbf{0}$

Analysis time (sec) : $\mathbf{0 . 6 4}$

Table 3 Topological measures of the firm's co-patenting core network

Analyzing this network, we can observe that large-very large firms are more closely related to other firms, whereas small-medium firms are more peripheral, and this is confirmed by the centrality parameters shown in Table 4 . Based on firms with the top 40 highest eccentricity indices, we can observe that only 8 of these (highlighted in the table) are SMEs, while the other 32 firms are all large or very large firms. This implies that all firms in the co-patenting network are in proximity with large-very large firms, suggesting that they play a more 
important role in nanotechnology's knowledge transfer model than do small-medium firms. These 32 large-very large firms have also high betweenness indices, suggesting they may act as gatekeepers and/or connectors in nanotechnology networks. We can therefore say that large-very large firms seem to play a central role in the process of co-production of knowledge, so, in contrast with proposition 1, proposition 2 seems to be confirmed. 


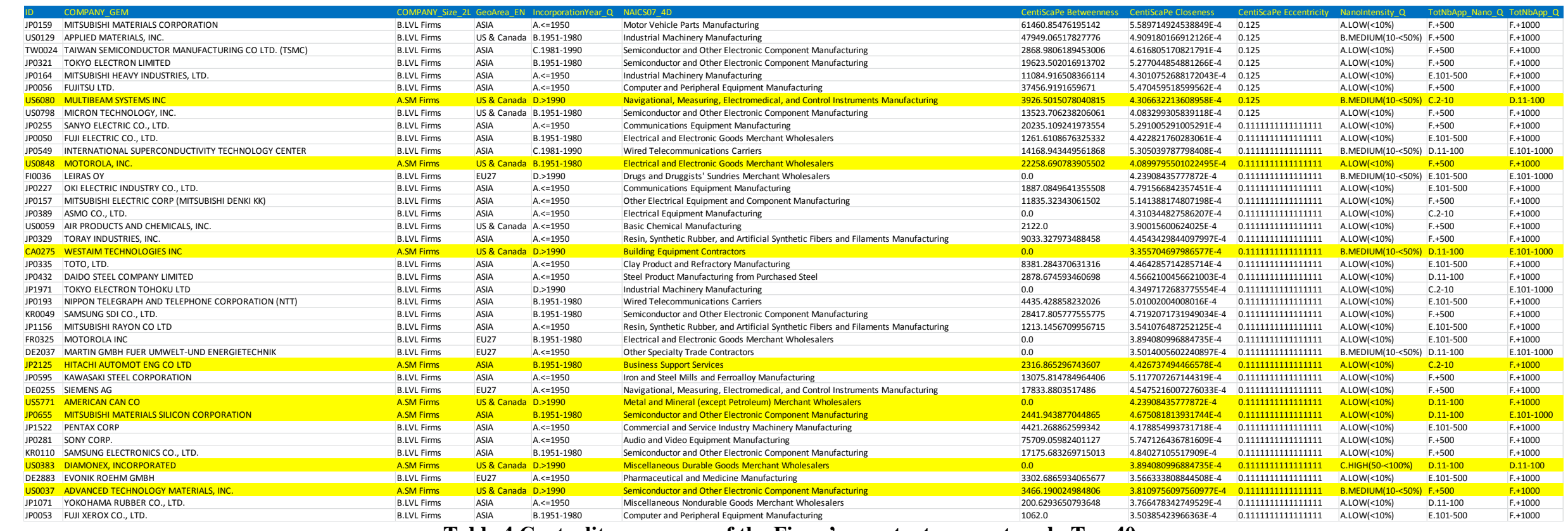

Table 4 Centrality measures of the Firms' co-patent core network-Top 40- 


\section{Conclusions}

Our results show first that the model of technology transfer is very different from that of biotechnology. Contrary to what happened in the development of the biotech sector, small and medium nanotech firms play an important technology-bringing role, but do not play the key role as translator of new knowledge between public research and industry. We know that small firms provide specific equipment and research services to very large companies: indeed, working at the nanotech level requires specific equipment, simulation models, first generation materials, devices and software. The nanotech-value chain is supported by a set of tools including scanning probe microscopes, nanofabrication tools, and computer modeling systems. Following Rosenberg's (1992) argument that scientific instruments can enable technologies that fuel subsequent down-stream discoveries, specific equipment, simulation models and specialized software play a similar role in nanotechnology $R \& D$, and these are elements that are typically developed and commercialized by small firms. Government investment in the biotech sector was mainly channeled through supporting the creation of start-ups: but while this was quite successful in boosting technology transfer and the commercialization of $\mathrm{R} \& \mathrm{D}$ in that context, public policies designed to support nanotechnologies needs to be designed differently.

Our results reveal, secondly, that nanotechnology is being developed within large firms, along the same pattern seen in the early phases of microelectronics, since nanotech development requires the kind of large and diversifies knowledge bases that exist in large firms. At the current stage of nanotechnology evolution, the process of exploration and knowledge translation are based mainly on collaboration patterns inherited from earlier forms of industrial organization. In microelectronics, government was both the principal organizer and a major source of funding of large-scale research project - and in the same way, over $\$ 3 \mathrm{bn}$ of government money world-wide has been pumped into the development of nanotechnologies during the last couple of years, even though they are still in the early stage of their technological life cycles. However, they promise exciting long-term pay-offs to those governments that do invest. 


\section{References}

Abernathy WJ, Utterback J. (1978). Patterns of Industrial Innovation. Technology Review 80: 41-47

Arcangeli F, Dosi G, Moggi M. (1991) Patterns of diffusion of electronics technologies: An international comparison with special reference to the Italian case, Research Policy 20 (1991) 515529.

Braun E. And MacDonald S. (1978), Revolution in Miniature: The history and Impact of Semiconductor Electronics. Cambridge: Cambridge University Press.

Albert R and Barabasi A-L (2002), Statistical Mechanics of Complex Networks, Review of Modern Physics, 74, 47-97.

Chachamidou M., Logothetidis S. (2008) "Spin-off creation behavior of universities and research institutions: an initial approach for nanotechnology”, Int. J. Technology Transfer and Commercialization, Vol. 7, No.4.

Chen H., Roco M.C. (2009) "Mapping nanotechnology innovations and knowledge - Global and Longitudinal Patent and Literature Analysis", Springer Science+ Business Media, New York.

Gambardella A., (1995) Science and Innovation. Cambridge University Press, Cambridge.

Goetze C. (2010) An empirical enquiry into co-patent networks and their stars: The case of cardiac pacemaker technology. Technovation 30, 436-446.

Greis, N.P., Dibner, M.D., Bean, A.S., (1995). External partnering as a response to innovation barriers and global competition in biotechnology. Research Policy 24 (4), 609-630.

Hill CWL, Rothaermel FT. (2003). The Performance of Incumbent Firms in the Face of Radical Technological Innovation. Academy of Management Review 28(2): 257-274

Kenney M. (1986), Biotechnology : The University-Industrial Complex, Yale University Press, New Haven and London.

R. Levin. The Semiconductor Industry. in: R. Nelson (ed.) Government and Technical Progress (Pergamon Press. 1982).

Linton J.D. and Walsh S.T. (2004) Integrating innovation and learning curve theory: an enabler for moving nanotechnologies and other emerging process technologies into production, $R \& D$ Management 34, 5, 2004.

Mangematin V.; Lemarié S., Boissin J-P, Catherine D., Corolleur F., Coronini R., Trommetter M. (2003) Development of SMEs and heterogeneity of trajectories: the case of biotechnology in France, Research Policy, 32 (2003) 621-638.

Mangematin V, Errabi K, Gauthier C (2010), Large players in the nanogame: dedicated nanotech subsidiaries or distributed nanotech capabilities? Journal of Technological Transfer, forthcoming. 
Mangematin V., Rieu C. 2010. The Determinants of Science-Based Cluster Growth: The case of Nanotechnology. RMT Working paper series.

Mougotov A., Kahane B. (2007) Data Search Strategy for Science and Technology Emergence: A Scalable and Evolutionary Query for Nanotechnology Tracking, Research Policy, 36, 6.

Mowery D.C. (1983) Innovation, market structure, and government policy in the American semiconductor electronics industry: A survey, Research Policy, 12 (1983) 183-197.

Niosi J. and Reid S.E. (2007) Biotechnology and Nanotechnology: Science-based Enabling Technologies as Windows of Opportunity for LDCs? World Development Vol. 35, No. 3, pp. 426438,2007

Orsenigo L. (1989) The emergence of biotechnology, Pinter Publishers, London.

Orsenigo, L.; Pammolli, F. and Riccaboni, M. "Technological Change and Network Dynamics. Lessons from the Pharmaceutical Industry." Research Policy, 2001, 30, pp. 485-508.

Peck M. (1986) Joint R\&D: The case of Microelectronics and Computer Technology Corporation, Research Policy 15 (1986) 219-231.

Pyka A. and Saviotti P.P. (2005) The evolution of R\&D networking in the biotech industries, International Journal of Entrepreneurship and Innovation Management, Vol. 5, No 1-2, p. 49 - 68, 2005 .

Roco, M.C., Williams, R.S. and Alivisatos, P. (Eds) (2000). Nanotechnology Research Directions, Kluwer Academic Publishers, Boston.

Rosenberg N, (1992), Scientific Instrumentation and University Research, Research Policy 21, 381397.

Rothaermel F.T. and Thursby M. (2007) The nanotech versus the biotech revolution: Sources of productivity in incumbent firm research, Research Policy 36 (2007) 832-849.

Sharp M. (1985), The New Biotechnology: European Governments in Search of a Strategy, Sussex European Papers, Brighton, University of Sussex.

Shea CM. (2005) Future Management Research Directions in Nanotechnology: A Case Study. Journal of Engineering and Technology Management 22(3): 185-200

Walsh S. ; Kirkoff B.; Newbert S. (2002) Differentiating market strategies for disruptive technologies, IEEE Trans. Engin. Manage. 49 (4) (2002) 341-351.

Wasserman S and Faust K (1994), Social Network Analysis: Methods and Applications, Cambridge University Press, Cambridge.

Youtie J. et Shapira P. (2008) Mapping the nanotechnology enterprise: a multi-indicator analysis of emerging nanodistricts in the US South, Journal of Technology Transfer (2008) 33:209-223 
Zucker, L., Darby, M., 1997. Present at the revolution: transformation of technical identity for a large incumbent pharmaceutical firm after the biotechnological breakthrough. Research Policy 26, 429446.

Zucker LG, Darby M, Furner J, Liu RC, Ma H. (2007). Minerva Unbound: Knowledge Stocks, Knowledge Flows and New Knowledge Production. Research Policy 36(6): 850-863 